\title{
Clinical and electron microscopic studies of a case of glycolipid lipoidosis (Fabry's disease)
}

\author{
ANGUS I. RAE, JOHN C. LEE, AND JAMES HOPPER, JR. \\ From the Departments of Medicine and Pathology, University of California School of Medicine, \\ San Francisco, California, U.S.A.
}

SYNOPSIS A case of glycolipid lipoidosis (Fabry's disease) in a 27-year-old man is recorded. The case is unusual in that despite extensive disease evidenced by widespread skin lesions, ocular abnormalities, and proteinuria, renal function was only minimally impaired. Electron microscope studies of kidney and skin showed that most cells contained the characteristic lipid described in this condition.

Angiokeratoma corporis diffusum universale, first described by Fabry in Germany and Anderson in England in 1898, is known eponymously as Fabry's disease. Recently the name glycolipid lipoidosis was suggested by Sweeley and Klionsky (1963) as being more appropriate. The condition is a hereditary abnormality of lipid metabolism dependent on a sexlinked gene with occasional penetrance in the heterozygous female and constant penetrance in the affected male (Dempsey, Hartley, Carroll, Balint, Miller, and Frommeyer, 1965). The majority of reports concern males who inherited the condition from their mothers, although a few cases in women have also been described (Colley, Miller, Hutt, Wallace, and de Wardener, 1958; Wallace, 1958; Rahman, Simeone, Hackel, Hall, Hirsch, and Harris, 1961; Wise, Wallace, and Jellinek, 1962). So far, the sons of affected men have been normal, whereas their daughters have been found to be carriers (Von Gemmingen, Kierland, and Opitz, 1965).

In glycolipid lipoidosis birefringent lipid accumulates extensively in cells throughout the body. The presence of the lipid in the media of blood vessels and in the kidney is responsible for those clinical manifestations of the disease that ultimately lead to death. The abnormal substance was first thought to be a phospholipid (Ruiter, 1954, 1957; Pittelkow, Kierland, and Montgomery, 1957). Recent studies, however, have shown an abnormally high concentration of two or more neutral glycolipids in the kidneys of these patients (Sweeley and Klionsky, 1963). Although a number of light microscopic studies have

Received for publication 26 July 1966. appeared (Colley et al., 1958; Bethune, Landrigan, and Chipman, 1961; Von Gemmingen et al., 1965) electron microscopic studies have been few (Henry and Rally, 1963; Hartley, Miller, Dempsey, and Carroll, 1964; Dempsey et al., 1965; McNary and Lowenstein, 1965). We are therefore reporting a further case in which electron microscopy was carried out.

\section{CASE REPORT}

A 27-year-old white man was referred to the University of California Medical Center in 1965 bzcause of 'a rash, a heart murmur, hypertension, and proteinuria'. At the age of 11 he had noticed red spots on the inside of his left arm. Over the next several years the red spots also appeared in increasing numbers on the lower back and over the abdomen. They caused no irritation, did not bleed and, since they did not occur on the face, in no way worried the patient. Proteinuria was first detected in 1953. In 1959 the patient was rejected as physically unfit for service in the Armed Forces; a skin biopsy at that time led to the diagnosis of angiokeratoma corporis diffusum. He had no complaints and did not seek medical advice again until March 1965. At that time his physician referred him to the Medical Center for evaluation.

At the time of admission, the patient was a tall, thin man who was alert, cooperative, and not unintelligent. His height was $188 \mathrm{~cm}$., as was his span. He weighed $65.4 \mathrm{~kg}$. The most striking abnormality was the skin rash, consisting of myriads of red to purple lesions measuring from pinpoint size to $1 \mathrm{~mm}$. in diameter. The majority were raised above the surface, and as the examiner ran his fingers over the affected areas it was as if he were running them over a cloth covered with salt grains. Most of the lesions were around the umbilicus and on the skin of the abdomen and lower back (Fig. 1). Fewer lesions, although 


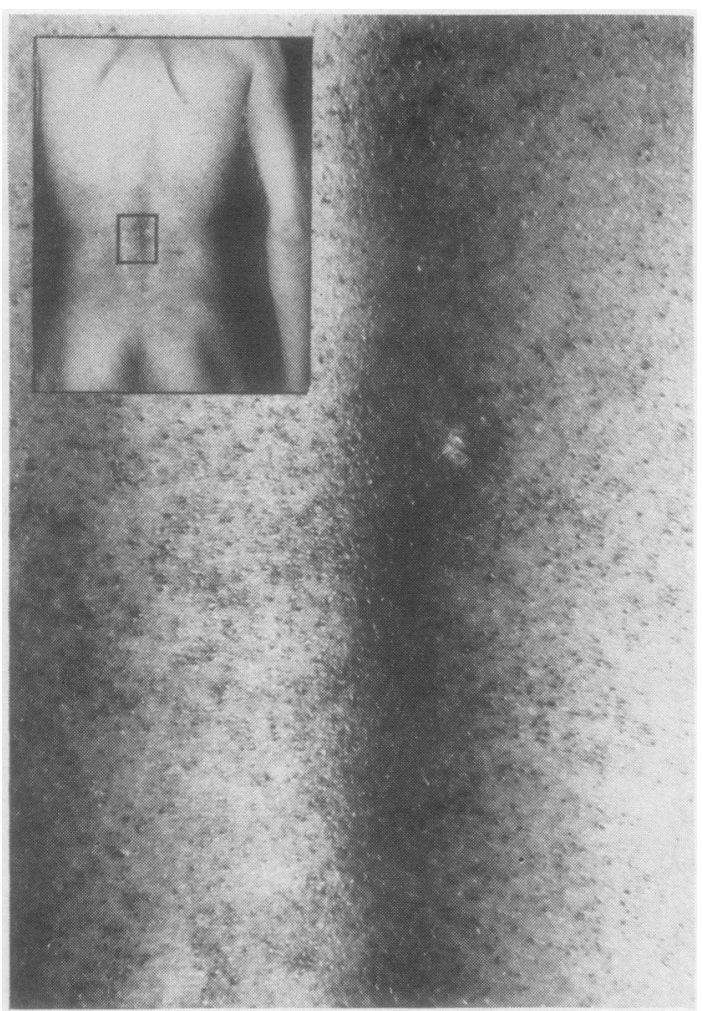

FIG. 1. Typical skin lesions of glycolipid lipoidosis seen in profusion over the patient's back.

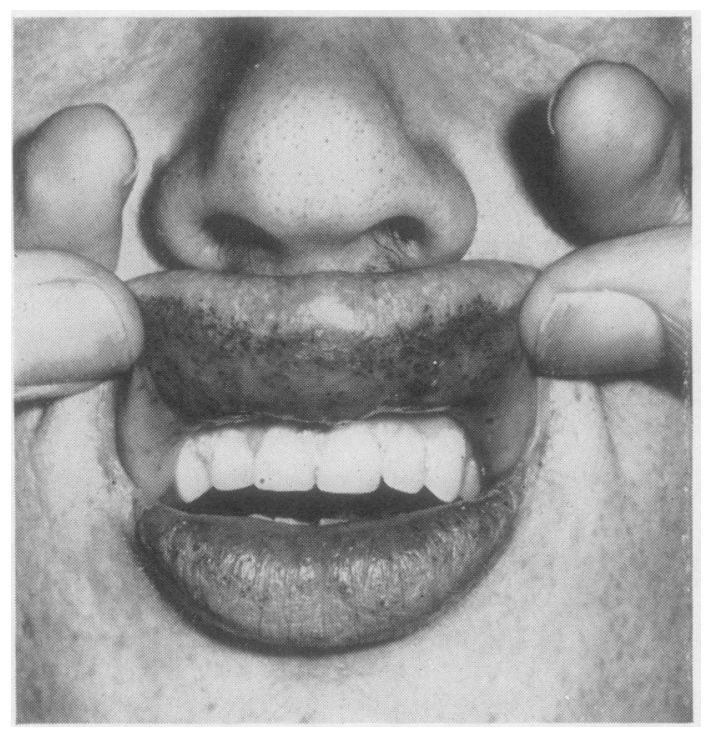

FIG. 2. Numerous lesions seen on the mucosa of the patient's lips. still many hundreds, were present over the buttocks, thighs, shaft of the penis, scrotum, upper trunk, and arms. In one area on the buttock hundreds of individual $\equiv$ lesions had coalesced, giving the superficial appearance of a naevus measuring $2 \times 1$ inch. A few lesions were presento on the palms of the hands, in the fingernail beds, on the scalp above the hairline, on the conjunctival surface of the $\overline{\bar{S}}$. eyelids, and at the inner canthus of each eye. A cluster was seen on the lobe of the right ear. The mucosal surfaces of the lips, which were typically prominent andes fleshy, were covered with lesions (Fig. 2). Fewer were $\overrightarrow{0}$ present on the buccal mucosa and the soft palate. Three- fingernails on the right hand showed the turtle-back $\vec{\omega}$ deformity that has been described in these patients (Dempsey et al., 1965).

When first examined the patient was extremely nervous. The pulse was $120 / \mathrm{min}$., and blood pressure $140 / 84 \mathrm{~mm}$. Hg. A 2/6 ejection systolic murmur was heard at the left sternal edge. On subsequent examination the pulse rate was $80 / \mathrm{min}$., the blood pressure $120 / 75 \mathrm{~mm} . \mathrm{Hg}$, and the bruit was no longer audible. No abnormalities of thechest, abdomen, or central nervous system were found.

The patient was myopic. The conjunctival vessels were? tortuous with small aneurysmal dilatations. Slit-lampô examination showed a faint whorled pattern in the epithelium of the cornea. The retinal veins showed the $\vec{c}$ striking irregularity in calibre which has led to their beingo likened to a string of sausages. The fundal arteries appeared normal, as did the optic discs. No haemorr-o hages or exudates were seen. He had no defect in hearing as shown by audiometry, unlike patients with other forms of hereditary nephritis (Williamson, 1961). The patient said he preferred cool weather and claimed that he never sweated. He denied acral pain, paraesthesiae, diarrhoea, fever, or urinary tract symptoms.

The packed cell volume was $40 \%$. The total white blood cell count was 6,500 per c.mm., with a norma屏 differentialcount. The serum creatinine was $1 \cdot 2 \mathrm{mg} . / 100 \mathrm{ml}$. and the blood urea nitrogen $12 \mathrm{mg} . / 100 \mathrm{ml}$. Serum albumin was 3.7 and globulin $2.7 \mathrm{~g} . / 100 \mathrm{ml}$. The serump protein electrophoretic pattern was unremarkable. The serum cholesterol was $192 \mathrm{mg} . / 100 \mathrm{ml}$. Twelve-hour: endogenous creatinine clearance, corrected to a bodyô surface area of $1.73 \mathrm{M}^{2}$, was $85 \mathrm{ml}$./min. Urinary excretion of protein was $3.3 \mathrm{~g}$. $/ 24 \mathrm{hr}$., and the sediment contained 20 granular casts, 10 to 15 red blood cells, and 10 to 15 white blood cells per high-power field. A number of renato epithelial cells containing birefringent fat globules were. seen. A urine culture was sterile. After 18 hours of fluid deprivation the patient was able to concentrate the urine to specific gravity $1 \cdot 015$. Exocrine gland function waso studied (Maibach, Khan, Strauss, and Pearson, 1966) with a modified Bullard sudorimeter. The results showedo that the patient was totally anhidrotic except for the palms, axillae, and forehead. Chest radiograph, intravenous pyelogram, and electrocardiogram showed nos abnormalities.

\section{FAMILY HISTORY}

None of the patient's grandparents was living. Both of his paternal grandparents had died of 'strokes', one at 69 
years and the other at 75 years of age. His maternal grandfather had been killed in the San Francisco earthquake of 1906. The caues of his maternal grandmother's death was not known.

The patient's mother, sister, and two maternal aunts were examined. No evidence of rash was found, nor did their urine contain lipid. All were normotensive except one aunt who was under treatment for mild hypertension and proteinuria, said to have followed toxaemia of pregnancy. The patient's mother had a corneal lesion similar to that of her son. None of the other female relatives showed corneal changes.

The patient's 33-year-old brother, 62-year-old maternal uncle, and 61-year-old father refused to be examined. They were alleged to be in good health, and all were well past the age at which symptoms of glycolipid lipoidosis usually appear. Examination of one other male relative, the 10-year-old son of the patient's sister, showed a cluster of punctate red spots on the left arm above the elbow; no other abnormalities were found.

\section{HISTOPATHOLOGY}

MATERIALS AND METHODS Specimens of tissue were obtained from the patient's left kidney by percutaneous biopsy. Biopsy specimens of skin were also taken from the left flank.

A portion of each tissue was fixed in $10 \%$ Zenkerformol and embedded in paraffin for light microscopy. Sections 4 to $5 \mu$ thick were stained with haemotoxylin and eosin, Masson's trichrome, Sudan Black B, and by the periodic-acid-Schiff reaction. For electron microscopy the remaining portions of each tissue were fixed for 12 hours in cold $1.5 \%$ distilled glutaraldehyde buffered to pH $7 \cdot 4$ with $0 \cdot 1 \mathrm{M}$ sodium cacodylate, as described by Sabatini, Bensch, and Barrnett, 1963; Sabatini, Miller, and Barrnett (1964). The tissues were then placed in $1 \%$ osmium tetroxide for one and a half hr. (Millonig, 1961), dehydrated in alcohol, and embedded in epoxy resin (Luft, 1961). Thin sections were stained with uranyl acetate and lead hydroxide and examined with a Siemens' Elmiskop I electron microscope.

RESULTS BY LIGHT MICROSCOPY In the kidney sections the interstitial connective tissue was moderately increased and contained a few plasma cells, lymphocytes, and macrophages. There was also moderate intimal fibrosis of small arteries and focal nephron atrophy with occasional hyalinized glomeruli. A striking histological feature was the marked vacuolation of the cytoplasm of glomerular epithelial cells, tubular epithelium, and macrophages of the interstitium (Fig. 3). The vacuoles did not take up any of the stains. Most glomeruli were otherwise unchanged except for some periglomerular fibrosis and thickening of the axial stalk. Frozen sections were not stained for lipid.

In the skin sections small aggregates of markedly dilated thin-walled capillaries were seen in the papillae of the superficial dermis. The surface

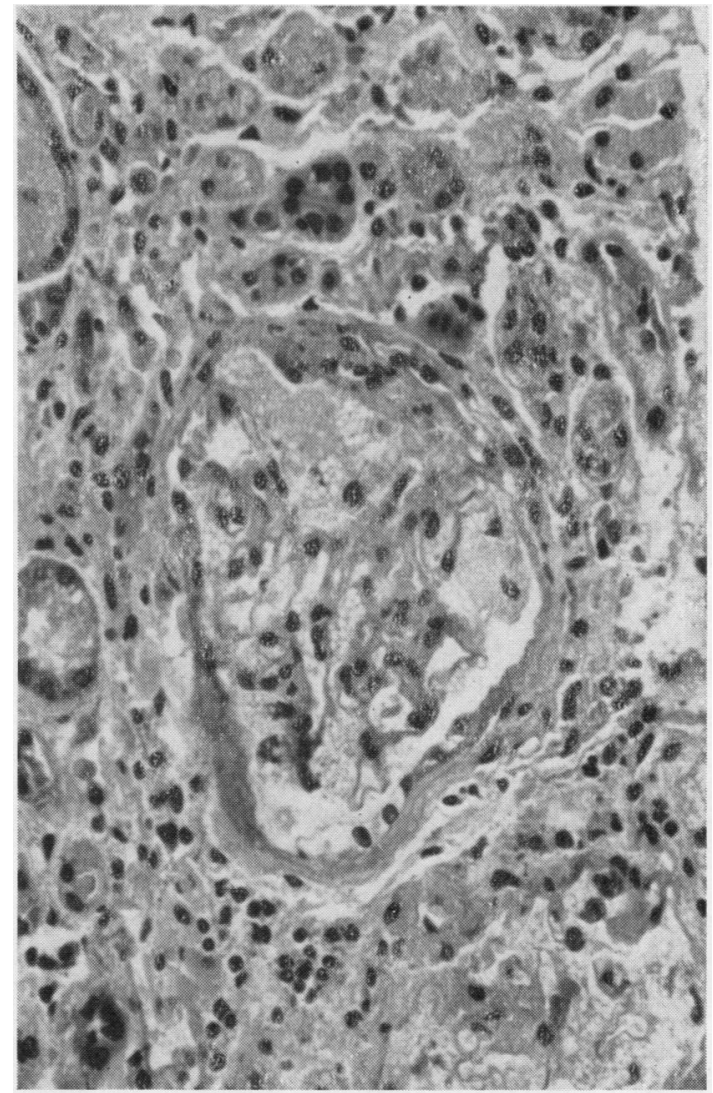

FIG. 3. Photomicrograph of renal cortex demonstrating the typical 'foam-cell' appearance of the glomerular epithelium and lymphocytic infiltration of the interstitium. Vacuoles are also prominent in tubular epithelium. Haematoxylin and eosin $\times 100$.

stratified epithelium appeared normal. The cytoplasm of dermal histiocytes showed considerable vacuolation. No sweat glands were seen.

ELECTRON MICROSCOPY In the kidney sections the glomerular basement membrane appeared of uniform thickness and showed no abnormal features. A moderate increase in basement membrane-like material was noted within the mesangium. Numerous osmiophilic inclusions were seen in all cellular components of the kidney, but were most noticeable in the glomerular endothelium and epithelium (Fig. 4). Fewer inclusions were seen in the renal tubular epithelium and interstitial tissue histiocytes and fibrocytes. Some inclusions were large, measuring as much as $1.5 \mu$ in diameter. All inclusions were bound by a single membrane and were amorphous or made up of membrane arrays resembling myelin figures or 


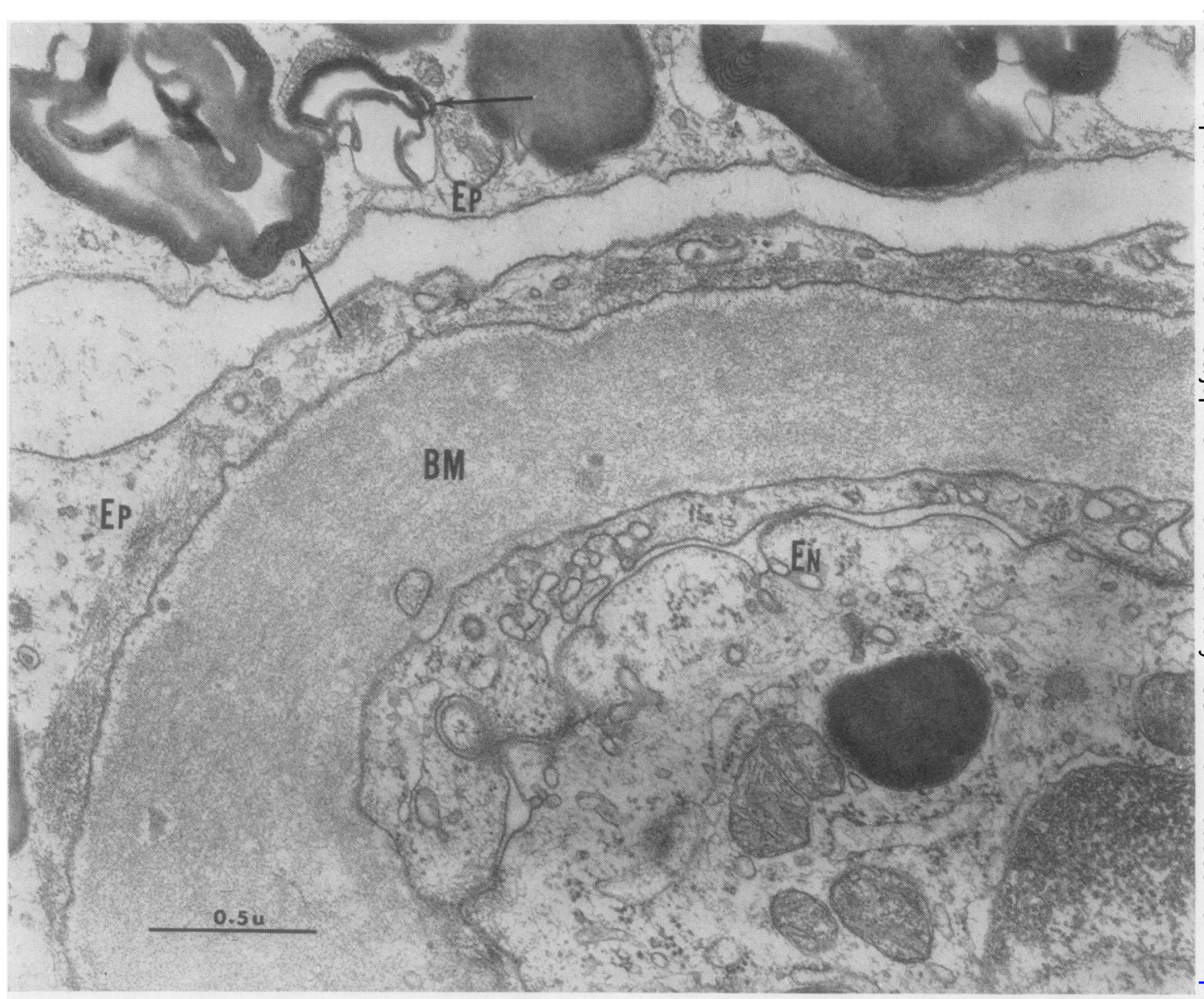

FIG. 4. Electron micrograph of a portion of a glomerulus, showing several large electron-dense inclusions within the glomerular epithelium (EP) and endothelium $(E N)$. Many inclusions have a parallel membrane-like appearance resembling myelin (arrows). The basement membrane (BM) appears within normal limits; however, epithelial cell foot processes $Э$ have been lost. $\times 69,300$.

showed a lattice-like crystalline structure of variable periodicity (51 to $98 \AA$ ).

The biopsy specimens of skin showed similar inclusions in great profusion in the endothelium and in pericytes of the small dermal capillaries. Again, inclusions were present in all cells including fibrocytes (Fig. 5).

\section{DISCUSSION}

CLINICAL FEATURES The most characteristic feature of Fabry's disease is the unusual skin rash, as seen in our case. The diagnosis has not been made clinically in its absence. Its cause is not known. The rash consists of numerous dark red angiokeratomas, some pinpoint in size and flat, and others larger, raised from the surface and appearing like droplets $\stackrel{\circ}{5}$ lying on rather than in the skin. The lesions may $\frac{D}{0}$ occur on any part of the body except the face, but have a predilection for the area between the umbilicus $N$ and the knees and a tendency to bilateral symmetry. $N$ Similar lesions may occur on the mucous membranes of the mouth and on the conjunctivae, as well as on $\omega$ the palms of the hands and in the nail beds (Yu Kuang-Yuan, 1956). They have been seen at necropsy을 in the respiratory, gastrointestinal, and genito-urinary tracts (Scriba, 1950). The rash appears during child-hood as small groups of individual lesions and $\frac{T}{0}$ gradually spreads. It does not itch. The lesions may bleed a little when subjected to trauma, but the $\stackrel{?}{\mathcal{T}}$ bleeding is never severe. Since our patient is virtually 2 symptom free, has a normal blood pressure and only 


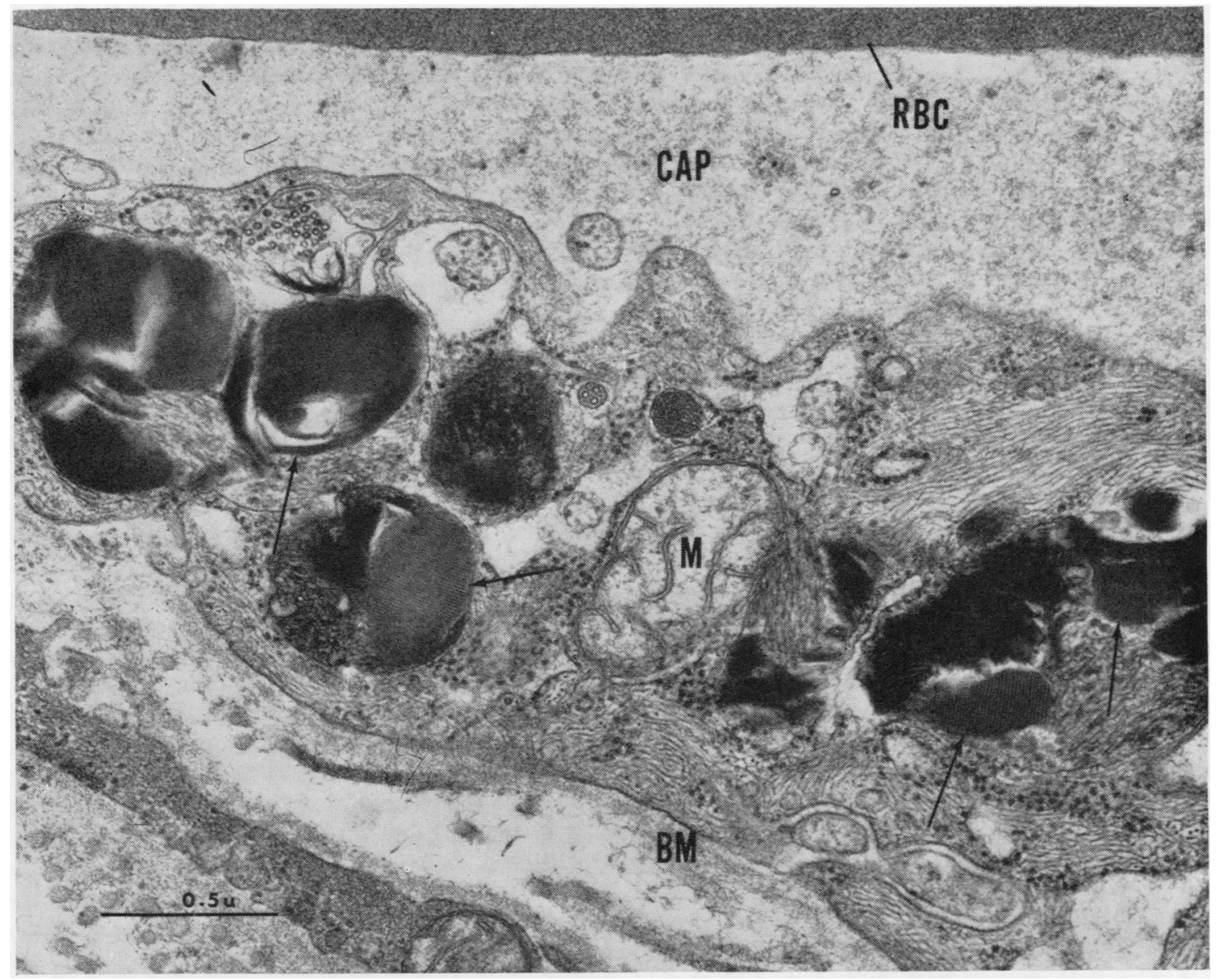

FIG. 5. Electron micrograph of dermal capillary endothelium showing many inclusions. Some inclusions have an amorphous appearance whereas others have a distinct lattice-like structure (arrows) with variable periodicity ranging from 51 to $98 \AA$. $M=$ mitochondria; $C A P=$ capillary lumen; $B M=$ capillary basement membrane; $R B C=$ red blood cell. $\times 72,600$.

minimal impairment of renal function, the extent of the skin lesions is evidently a poor index of the severity of the disease.

Patients with glycolipoidosis have a number of symptoms, the causation of which is not clearly understood. Epistaxis and haemoptysis have been described (Calas, Mafard, and Mathurin, 1957) but may have been coincidental findings. Hypohidrosis, which was present in our case, may result from some abnormality of the sweating mechanism and could account for the discomfort these patients have during warm weather. A paucity of sebaceous and sweat glands in the skin has been described by Cunningham and Krauel (1957). Von Gemmingen et al. (1965), however, were unable to confirm this finding. In the present case the biopsy specimens of skin, which were taken from the flank and may not be representative, contained no sweat glands. Episodes of fever may occur, associated at times with painful red swellings in the region of the joints. Since the erythrocyte sedimentation rate is increased, the condition may be mistaken for rheumatic fever (Sweeley and Klionsky, 1963). In the early phases pain in the fingers and toes, and occasionally in the tongue or glans penis (Wise et al., 1962), is a characteristic feature. The pain may be mild or excruciating and is often exacerbated by very warm or cold surroundings; it usually lessens as the disease progresses. In some cases abdominal pain may simulate appendicitis or renal colic (Rahman et al., 1961). Paraesthesiae may occur in the extremities. Oedema of the ankles is fairly common and appears before renal and 
cardiovascular involvement is sufficiently advanced to be implicated. Episodes of diarrhoea occur at times and may be severe enough to cause hypokalaemia (Rahman et al., 1961). Our patient had none of these complaints. Corneal dystrophy is a frequent finding. It is also an important clue in detecting the carrier state in females who have no other overt manifestations of the disease (Rahman et al., 1961; Rahman and Lindenberg, 1963; Von Gemmingen et al., 1965), as in our patient's mother who probably transmitted the abnormal gene to her son. The conjunctiveae and ocular fundi show the vascular abnormalties seen in our patient; in some cases the disc edges are blurred, suggesting papilloedema (Spaeth and Frost, 1965). Chronic bronchitis is not uncommon (Price, 1955; Wise et al., 1962), and dyspnoea associated with alveolar capillary block has been described (Parkinson and Sunshine, 1961).

Histological features Post-mortem findings in a case of Fabry's disease were first reported by Pompen, Ruiter, and Wyers (1948). To these investigators the vacuolation of smooth muscle cells of blood vessels and cardiac muscle fibres suggested a lipid storage disease. This hypothesis has since been confirmed by Fessas, Wintrobe, and Cartwright (1955), Wise et al. (1962), and Von Gemmingen et al. (1965). Foam cells filled with lipid have been reported in lymph glands and spleen (Scriba, 1950) and in bone marrow and urinary sediment (Fessas et al., 1955). Blood-filled lacunae surrounded by hyperkeratotic epidermis have been seen in biopsy specimens of skin (Von Gemmingen et al., 1965; Curry and Fleisher, 1961). Rahman and Lindenberg (1963) demonstrated lipid in many cells in the nervous system, particularly the autonomic nervous system, as well as in small cerebral blood vessels. The renal changes due to deposition of lipid were reported by Colley et al. (1958). They described fine vacuolation of the epithelial cells of the glomerular tuft, giving a honeycomb appearance. Similar vacuolation was seen in Bowman's capsule, the loops of Henle, and the distal tubules. Involvement of the distal tubules may have been responsible for their patient's inablity to concentrate the urine. In addition, they noted intimal thickening of interlobular arteries and oedema of the medial muscular coat, which also contained foam cells. Similar histological changes in the kidney were seen in our case and others reported in the literature (Bethune et al., 1961; Henry and Rally, 1963; Hartley et al., 1964).

Electron microscopic studies were first reported by Henry and Rally (1963). These investigators demonstrated lamellated osmiophilic material in the glomerular epithelial cells and distal convoluted tubules in the kidney. Similar material was seen in $\underline{\vec{\sigma}}$ the endothelial cells and media of blood vessels in the skin. Hartley et al. (1964) and Dempsey et al. (1965) also noted concentric lamellated structures in theo visceral epithelial cells or podocytes lying outside the 으 capillary basement membrane and somewhat less $\frac{\bar{p}}{\bar{D}}$ distinct bodies in the parietal epithelial cells of $\mathbb{8}$ Bowman's capsules and in the endothelial cells of the glomerular capillaries. Sagebiel and Parker (1966) ${ }^{\infty}$ commented on the similarity of the intracellular. lamellar structures seen in Niemann-Pick and Tay- $\overrightarrow{\vec{\omega}}$ Sach diseases and in Fabry's disease. Electron $\stackrel{\omega}{\omega}$ microscopic studies in our case showed these struc- $\overline{ }$ tures in cells throughout the kidney, skin, and blood vessels.

LIPID DEPOSITION The material deposited in the cells undoubtedly is a lipid. It is soluble in routine fixation and processing for paraffin sections, result- $\overrightarrow{-}$ ing in the characteristic vacuolation in cells. It is preserved in osmium-fixed tissues, indicating that it $\frac{\vec{c}}{\mathrm{D}}$ is a lipid, but not necessarily a phospholipid as suggested by Ruiter $(1954,1957)$ and Pittelkow et al. $\overrightarrow{\mid}$ (1957). The lipid nature of the substance is confirmed by its staining characteristics with Sudan IV or oil ${ }^{*}$ red 0 in frozen sections. Sweeley and Klionsky (1963, 1966) were unable to demonstrate the diaminophosphatide referred to by Ruiter (1957). They did, however, establish the presence of two glycolipids in $\frac{O}{\varnothing}$ abnormally high concentrations in the kidney of a patient with Fabry's disease. The major one was a $\overrightarrow{\overrightarrow{0}}$ ceremide trihexose containing one molecule each of 3 sphingose and glucose and two molecules of galactose. This substance is similar in configuration to the ceremide trihexose found in small quantities in $\overline{7}$ normal kidney and other tissues (Mårtensson, 1963). The second glycolipid, present in lesser quantities, 3 was a dihexose containing two moles of galactose; it also contained sulphur. Neither glycolipid contained phosphorus. Dempsey and co-workers (1965) demonstrated a relative diminution of phospholipid in the red blood cells of one of their patients although the plasma lipids were normal. The significance of this finding is not clear.

The widespread deposits in cells of blood vessels, $N$ skin, kidneys, central nervous system, and elsewhere $N$ suggests either excessive production of these substances or inability of enzyme systems to degrade them. Little is known of the enzymatic mechanisms utilized in degrading glycolipids.

The lipid accumulations are particularly prominent in the kidney, in the smooth muscle cells of the media of small blood vessels, and in the myocardium. It is damage to these structures that eventually leads $\frac{\stackrel{\rho}{\mathbb{D}}}{\sigma}$ to the patient's death in the fourth or fifth decade 2 and sometimes earlier. The majority of patients are 
dead by the age of 50 ; the few who survive beyond this age usually have relatively little impairment of renal function (Bethune et al., 1961; Fone and King, 1964). The prognosis cannot be predicted in our patient. The minimal impairment of renal function is regarded as a favourable sign; however, renal function could deteriorate or cerebral infarction could occur at any time.

As suggested by Hartley et al. (1964), the renal vascular involvement is probably the most important cause of progressive renal failure and hypertension. Uraemia was first described in such patients by Robba (1936), and renal failure is the most frequent cause of death. Proteinuria, cylindruria, and lipiduria are early manifestations of renal involvement. Polyuria may be a prominent feature of the disease at a stage when the glomerular filtration rate is relatively normal (Colley et al., 1958; Henry and Rally, 1963). It has been attributed to lipid deposits in the distal tubules.

Cerebral infarction, due either to hypertension associated with chronic renal disease or involvement of small blood vessels, is common (Rahman and Lindenberg, 1963). Cardiac infarction was reported in one 30-year-old patient (Fone and King, 1964).

Lipid deposits in the autonomic nervous system could account for abnormalties in the sweating mechanism, as well as the episodes of diarrhoea in such patients. Wise et al. (1962) consider that lipid involvement of the peripheral nerve endings probably is responsible for the pain in the early stages of the disease, although other investigators attribute it to a peripheral vascular phenomenon (Hartley et al., 1964).

The authors wish to acknowledge the technical help of Miss Miriam Duschkin who prepared the electron microscopic material and to thank Dr. Michel Campiche and the Cardiovascular Research Institute for use of electron microscope facilities.

This work was supported in part by grants from the U.S. Public Health Service (AM-06579 and HE-06285) from the Marin and San Mateo County Heart Associations, and from the Samuel B. McKee Fund, allocated by the Committee on Research, University of California School of Medicine. One of us (A.I.R.) is the recipient of a full-time grant from the Lederle International Fellowship Foundation.

\section{REFERENCES}

Anderson, W. (1898). Brit. J. Derm., 10, 113.

Bethune, J. E., Landrigan, P. L., and Chipman, C. D. (1961). New Engl. J. Med., 264, 1280.

Calas, E., Mafard, and Mathurin (1957). Bull. Soc. franc. Derm. Syph., 64, 682 .

Colley, J. R., Miller, D. L., Hutt, M. S. R., Wallace, H. J., and de Wardener, H. E. (1958). Brit. med. J., 1, 1266.

Cunningham, R. S., and Krauel, L. H. (1957). Northw. Med. (Seattle), $56,170$.

Curry, H. B., and Fleisher, T. L. (1961). J. Amer. med. Ass., 175, 864

Dempsey, H., Hartley, M. W., Carroll, J., Balint, J., Miller, R. E., and Frommeyer, W. B., Jr. (1965). Ann. intern. Med., 63, 1059.

Fabry, J. (1898). Arch. Derm. Syph. (Berl.), 43, 187.

Fessas, P., Wintrobe, M. M., and Cartwright, G. E. (1955). Arch. intern. Med., 95, 469.

Fone, D. J., and King, W. E. (1964). Aust. Ann. Med., 13, 339.

Hartley, M. W., Miller, R. E., Dempsey, H. J., and Carroll, J. F. (1964). Alabama J. med. Sci., 1, 361.

Henry, E. W., and Rally, C. R. (1963). Canad. med. Ass. J., 89, 2 C6

Yu Kuang-Yuan (1956). Chin. med. J., 74, 478.

Luft, J. H. (1961). J. biophys. biochem. Cytol., 9, 409.

Maibach, H. I., Khan, A. A., Strauss, W. G., and Pearson, T. R. (1966). Arch. Derm. 94, 215.

Mårtensson, E. (1963). Acta chem. scand., 17, 2356.

McNary, W. F., and Lowenstein, L. M. (1965). J. Urol., 93, 641.

Millonig, G. (1961). J. appl. Phys., 32, 1637.

Parkinson, J. E., and Sunshine, A. (1961). Amer. J. Med., 31, 951.

Pittelkow, R. B., Kierland, R. R., and Montgomery, H. (1957). Arch. Derm. 76, 59.

Pompen, A. W. M., Ruiter, M., and Wyers, H. J. G. (1948). Acta med. scand., 128, 234.

Price, J. H. (1955). Brit. J. Derm., 67, 105.

Rahman, A. N., and Lindenberg, R. (1963). Arch. Neurol. (Chic.), 9, 373.

—, Simeone, F. A., Hackel, D. B., Hall, P. W., 3d, Hirsch, E. Z., and Harris, J. W. (1961). Trans. Ass. Amer. Phycns, 74, 366.

Robba, G. (1936). Boll. Soc. ital. Derm. Sif., 14, 223.

Ruiter, M. (1954). Dermatologica (Basel), 109, 273.

- (1957). Brit. J. Derm., 69, 137.

Sabatini, D. D., Bensch, K., and Barrnett, R. J. (1963). J. Cell. Biol., $17,19$.

—, Miller, F., and Barrnett, R. J. (1964). J. Histochem. Cytochem., $12,57$.

Sagebiel, R., and Parker, F. (1966). Clin. Res., 14, 273.

Scriba, K. (1950). Verh. dtsch. path. Ges., 34, 221.

Spaeth, G. L., and Frost, P. (1965). Arch. Ophthal., 74, 760.

Sweeley, C. C., and Klionsky, B. (1966). In The Metabolic Basis of Inherited Disease, edited by J. B. Stanbury, J. B. Wyngaarden, and D. S. Fredrickson, 2nd ed., p. 618. McGraw-Hill, New York.

-_ _- (1963). J. biol. Chem., 238, 3148.

Von Gemmingen, G., Kierland, R. R., and Opitz, J. M. (1965). Arch. Derm. Syph. (Berl.), 91, 206.

Wallace, H. J. (1958). Brit. J. Derm., 70, 354.

Williamson, D. A. J. (1961). Lancet, 2, 1321.

Wise, D., Wallace, H. J., and Jellinek, E. H. (1962). Quart. J. Med., $31,177$. 